\title{
Reflejos del derecho comunitario sobre el derecho nacional *.
}

\author{
Gustavo Zanini \\ Assistente de Direito Internacional Pablico na \\ Faculdade de Direito da Universidade de \\ São Paulo.
}

\begin{abstract}
SUMÅrro: Introducción. Capítulo I. El Nuevo Concepto de Soberania. Capítulo II. Naturaleza Jurídica de las Comunidades y Relación Derecho Comunitario y Derecho Nacional. Capítulo III. Competencia de la Corte de Justicia de las Comunidades Europeas. Capítulo IV. El Derecho Comunitario y la Jurisprudencia de la Corte de Justicia de las Comunidades.
\end{abstract}

\section{Introducción}

Uno de los objetivos de la realización, en Bogotá, de la Sesión Exterior de la Academia de Derecho Internacional de la Haya, ha sido el estudio de las Comunidades Europeas.

El examen del proceso de la integración económica y social europea debe, ante todo, ser efectuado a la luz de los Tratados que crearon sus instituciones comunitarias más importantes, o sea, el Tratado de 18 de abril de 1951, de Paris, concerniente a la Comunidad Europea del Carbón y del Acero, y los Tratados firmados en Roma, en 25 de marzo de 1957 que dieron nacimiento a la Comunidad

* Trabalho apresentado na sessão exterior da Academia de Direito Internacional de Haia, realizada em Bogotá, em junho de 1969. 
Económica Europea y a la Comunidad Europea de Energía Atómica, respectivamente. Se consolidaban de esta manera las ideas de Robert Schumann, expresadas en su Declaración de 9 de mayo de 1950. Pero hay que señalar las dificultades de la ejecución de estos Tratados para los seis Estados contratantes (Italia, Francia, Bélgica, Alemania, Holanda y Luxemburgo) en el periodo inicial.

En verdad, aquellos Estados tuvieron que enfrentar problemas de distinta naturaleza, es decir, sobre la politica de inversiones y ayuda financiera; las políticas de precios, sociales y laborales; la tarifa exterior común; la libre circulación de personas, servicios y capitales, y muchos otros. A estos factores propios es menester agregar el difícil equilibrio de la estabilidad de la producción. A este respecto Nicola Catalano expresa el siguiente pensamiento: "Si es verdad que el ideal europeísta constituye ante todo una instancia ideológica y política, no debe pasar inadvertido que la realización de un comienzo de integración europea (afortunado neologismo con el cual, como será mejor precisado más adelante, se quiere significar la creación de estructuras de tipo federal) ha podido ser realizada sola y exclusivamente en el sector económico. En efecto, la más tenaz resistencia pudo superarse precisamente en el sector económico, demostrando a quienes actúan en ese campo, la inexistencia de las ventajas emergentes de la creación de un gran mercado que permita el aumento de la capacidad competitiva, el reciproco desarrollo e incremento de actividades y producciones complementarias, pero que deje además, subsistentes, también aquellas actividades de carácter marginal, de otra manera destinadas a desaparecer en el ámbito restringido de los mercados nacionales"1.

1. Nicola Catalano, Aspectos Ideológicos, Económicos, Politicos y Jurídicos de la Integración Económica Europea, in Anuario Uruguayo de Derecho Internacional, n. IV. 1965/1966, pág. 40. 
Sin embargo, la creación de las Comunidades Europeas no constituyó solamente un factor de desarrollo económico, político y social para los Estados miembros. En efecto la complejidad de la materia exigiría un estudio más intenso desde el punto de vista doctrinario y práctico. Y el trabajo de los iusinternacionalistas (o comunitaristas) es lo de hacer indagaciones sobre el objetivo de estas comunidades, sus fuentes, su naturaleza jurídica y su jurisprudencia, hasta llegar a la conclusión de la existencia de un nuevo rango del derecho, es decir, el Derecho Comunitario cuyos principios son distintos de los del Derecho Internacional General.

Asimismo, el espiritu de los Tratados y la práctica de su ejecución ponen de rilieve una nueva concepción de Soberanía, con características diversas de las conocidas en el derecho clásico.

\section{CAPÍ́tUlo PRIMERO}

El nuevo concepto de soberania.

El aparecimiento de las Organizaciones Internacionales y más concretamente, teniendo en cuenta el estudio que estamos haciendo, la creación de las Comunidades Europeas, ha generado nuevas interpretaciones en lo que concierne el problema de la soberania.

De hecho, si la teoría clásica hace de la soberanía el criterio del Estado, o sea, en Derecho Internacional tradicional la soberanía significando un conjunto de atributos y derechos "inherentes" a la personalidad del Estado, y por lo tanto, inalienables o indelegables, tenemos que admitir que tras el nacimiento del fenómeno comunitario europeo, el instituto jurídico ha recibido una interpretación nueva de su significado.

Realmente, para que la idea de la formación de las Comunidades Europeas se transformase en una realidad 
había que tener presente ante todo, la espontanea y libre transferencia de ciertos intereses de cada Estado miembro para la Comunidad.

EI sistema de derecho nacional de los distintos Estados miembros, por necesidad, reconoce la supremacía de las normas de Derecho Comunitario, y los órganos de la Comunidad son competentes para tomar decisiones "erga omnes". Se trata del criterio comunmente designado de supranacionalidad. Sobre este asunto Michel Gaudet nos aclara que "Las Comunidades Europeas han sido instituidas por Tratados que han sido objeto, en cada uno de los Estados miembros, de la aprobación parlamentaria y de la ratificación en la forma prevista en las disposiciones constitucionales en vigor."

"El establecimiento de las Comunidades, por lo tanto, resultó de un acto diplomático clásico mediante el cual los Estados contratantes se obligaron recíprocamente con el objetivo de mejorar las relaciones internacionales, especialmente por medio de la creación de una organización común con la capacidad de actuar en determinados asuntos. Así, la soberanía de los Estados se ejerce mediante la libre adhesión a un sistema de obligaciones mútuas y con un objetivo común."

"En la celebración de los Tratados que instituyeron las Comunidades Europeas no hubo la necesidad de resolver problemas constitucionales especiales."2

En este orden de ideas, cabría apreciar ahora las disposiciones constitucionales de los Estados miembros de las Comunidades Europeas en lo que concierne a los problemas de la soberanía. Realmente, es a través de la sistemática constitucional de los países comunitarios, relacio-

2. MICHEL GAUDET, Información sumaria sobre la "Cuestión Constitucional" en los seis Estados Miembros de las Comunidades Europeas, in La Integración da América Latina y la Cuestión Constitucional, Washington, 1967, pág. 75. 
nados con los Tratados que podremos comprender como será posible la transferencia de atribuciones soberanas de un Estado para una Comunidad internacional.

El primer examen que debemos efectuar es lo de hacer referencia a la Ley Fundamental (Grundgesetz) alemana cuyo artlculo 24 establece: "La Federación podrá transferir por vía legislativa los derechos de soberanía a instituciones internacionales." Lo que se observa en esta regla jurídica de naturaleza constitucional es que la República Federal de Alemania atribuye el ejercicio de competencias a un órgano supranacional, teniendo en cuenta la supremacía de las normas comunitarias sobre su derecho interno.

Basandose en este principio constitucional incontestable se puede concluir que el Estado Alemán no renuncía toda su soberanía, pero solamente, y por vía legislativa, permite la transferencia de algunas atribuciones para que la Comunidad pueda alcanzar sus objetivos comunes, o sea, la Integración Económica de los seis Estados miembros.

Análogo razionamiento podrá aplicarse a la Constitución Francesa de 1958. Realmente, el Preambulo de esta Constitución, cuyo texto es el mismo de la de 1948 enuncía:

"Bajo la reserva de reciprocidad, Francia consciente en las limitaciones de soberanía necesarias a la organización y a la defensa de la paz."

Hay que señalar que estos dispositivos constitucionales franceses no se refieren directamente a organismos supranacionales, pero "existen en ellos una referencia de segundo grado", conforme observa Michel Gacdet. ${ }^{3}$

Al hacer el análisis del artículo 11 de la Constitución italiana se puede constatar de imediato las expresas referencias sobre las limitaciones de su soberania en lo que se

3. Michel Gaudet, cp. cit., pág. 79. 
refiere a las organizaciones internacionales. De hecho, declara aquel artículo que Italia,

"en condiciones de reciprocidad con los demás Estados, acepta las limitaciones de su soberania que sean necesarias para el establecimiento de un orden que asegure la paz y la justicia entre las naciones. Ayuda y favorece a las organizaciones internacionales que persiguen esa finalidad."

Reconociendo en efecto, la amplitud del problema y sus intereses Italia acoge el principio de la restricción de soberanía, con el objeto de apoyar el desarrollo de las organizaciones internacionales.

En lo que se refiere a los Países Bajos, la materia que hace referencia a las normas internacionales figura en los artículos 63 y 67 de la respectiva Constitución que ha sido revisada en 1953 y en 1956. Establece el artículo 63:

"Cuando la evolución del orden jurídico internacional así lo exija, el tratado podrá revogar las disposiciones de la Constitución. Tal derogación debe ser aprobada expresamente; las Cámaras de los Estados Generales solo podrán adoptar un proyecto de ley referente a esta cuestión por mayoría de dos tercios de los votos emitidos."

Y declara el artículo 67:

"Observadas en cada caso las disposiciones del artículo 63, las facultades en los asuntos de legislación, de administración $\mathrm{y}$ de jurisdicción pueden ser delegadas por una convención o en virtud de una convención a las organizaciones de derecho internacional."

Por lo tanto, las cuestiones verdaderamente importantes y utiles de las normas constitucionales holandesas 
(la posibilidad de derogación, mediante la aprobación expresa de las Cámaras y la delegación de facultades a los organismos internacionales) responden a una exigencia fundamental del Derecho Internacional, y concretamente, del Derecho Comunitario.

La quinta Constitución que debemos analisar es la de Bélgica en la cual existe una omisión en lo que se refiere a normas tendientes a delegar atribuciones de soberanía a organizaciones internacionales.

Pero si el artículo 25 de dicha Constitución determina que "Todos los poderes emanan de la Nación y los mismos son ejercidos en la forma establecida por la Constitución", hay que subrayar que el artículo 68 preve la aprobación de Tratados mediante la "votación de una ley ordinaria."

Para completar este estudio de la materia, es necesario examinar la Constitución de Luxemburgo, la cual, en los artículos 37 y 49 , autoriza la transferencia temporal de derechos de soberanía a una organización internacional, mediante una norma convencional.

Conviene añadir y resaltar, teniendo en cuenta el texto del artículo 37, que "los Tratados son aprobados por ley votada de acuerdo con las condiciones del artículo 114, quinto párrafo." El artículo 114, que se caracteriza por la peculiaridad de sus términos, reglamenta el problema de las revisiones constitucionales.

En el analisis que hemos realizado, nosotros comprobamos que los Estados miembros aprobaron normalmente los Tratados de las Comunidades Europeas, apoyandose en la conciencia de una efectiva solidaridad y una colaboración voluntária entre ellos, otorgando una soma respectable de intereses, pero manteniendo, con algunas restricciones, la soberanía como personas de derecho internacional. 


\section{CAPÍTULO SEGUNDO}

\section{Naturaleza jurídica de las comunidades y relación derecho comunitário y derecho nacional}

Habiendo admitido que los Estados miembros de la Comunidad han restringido su soberanía para la creación de una entidad jurídica autónoma, nos encontramos ahora en presencia del problema, aun tan discutido, de saber cual es realmente la naturaleza jurídica de esta misma entidad.

Los autores más categorizados en esta materia han establecido criterios diversos para explicar la esencia del sistema de derecho de las Comunidades y el fenómeno de la supranacionalidad. De ahí la necesidad de hacermos indagaciones en torno a dos cuestiones: las fuentes y las teorías del Derecho Comunitario, como un nuevo rango del arbol jurídico.

En cuanto a las fuentes es de particular interés para la doctrina la clasificación hecha por el Profesor Nicola CATALANo ${ }^{4}$. Establece este autor dos categorias diferentes: a) las fuentes normativas directas y las fuentes normativas subsidiarias. Siguiendo este criterio los Tratados de las Comunidades con sus anexos y protocolos, las reglas de derecho relativas a su aplicación, por las Decisiones de la Alta Autoridad de la CECA y los Reglamentos de la CEE y el Eúratom, y los Acuerdos firmados por las Comunidades con terceros países constituyerían las fuentes normativas directas. Las fuentes normativas subsidiarias comprenderían las Disposiciones legislativas o Reglamentos aprobados por los Estados miembros.

4. Nicola Catalano, Manual de Derecho de las Comunidades Europeas, Intal, Buenos Aires, 1966, págs. 135 a 137. 
Con el objeto de delucidar sus ponderaciones, Catalano establece una otra clasificación en lo que respecta las fuentes normativas directas, sosteniendo que ellas pueden ser fuentes primarias (los Tratados), y fuentes secundarias (las Decisiones de la Alta Autoridad de la CECA y los Reglamentos de la CeE y el Euratom).

El examen de estas fuentes, a la luz de los principios jurídicos consagrados en los Tratados que instituyeron la Ceca, la Cee y el Euratom, nos lleva a las conclusiones seguientes:

1. ${ }^{\circ}$ - Los Tratados de las Comunidades Europeas constituyen una modalidad especial de contratación entre los Estados, caracterizada particularmente por la limitación de la soberanía de cada uno de ellos;

$20^{\circ}$ - Las Decisiones de la Ceca, por virtud del artículo 14 de su texto institucional, y los reglamentos de la CeE y el Euratom, por virtud de los artículos 189 y 161 de los Tratados respectivos, se afirman de modo categórico en los sistemas de Derecho Comunitario, teniendo en cuenta los principios de la obligatoriedad y de la ejecución.

Examinemos ahora las características de las teorías más expresivas que cercan de interpretar la relación entre el Derecho Comunitario y el Derecho Nacional.

\section{A) Teoría de la fundamentación propia del fenómeno Europeo.}

Según esta teoría, la solución de los conflictos entre los Tratados internacionales y el derecho nacional podría ser encontrada dentro de las reglas del sistema del Derecho Comunitario. 
$\mathrm{Al}$ examinar el informe relativo a la primacía del Derecho Comunitario sobre el Derecho de los Estados miembros, elaborado por la Comisión Jurídica del Parlamento Europeo se puede constatar que dicha Comisión ha defendido esta tésis bajo los siguientes argumentos: ${ }^{5}$

"El pretender resolver el problema de los conflictos entre el derecho comunitario y el derecho nacional mediante la utilización de los mismos medios que se aplican a los conflictos entre los tratados internacionales y el derecho nacional no constituye una solución perfecta. Seria más acertado y, por decirlo así, más científico, buscar una solución dentro de las características mismas del derecho comunitario. La característica predominante de la construcción comunitaria es que, tanto, en lo que se refiere a sus objetivos como en lo que respecta a los métodos, no es un sistema internacional de tipo clásico. Al analizar el derecho comunitario $y$, por consiguiente, el examinar las relaciones entre dicho derecho y el derecho nacional, los juristas no deben hacer caso omiso a las características de esa estructura en comparación con el derecho internacional clásico. En su origen se halla una voluntad y una finalidad de carácter político ligadas a la primacía del derecho comunitario y las únicas soluciones adecuadas son las que permiten deducir consecuencias de esa originalidad para justificar la primacía." (El subrayado es nuestro).

\section{B) Teoría procesalista.}

En lo tocante a la corriente doctrinaria llamada procesalista, explican sus defensores que los conflictos entre el derecho comunitario y el derecho interno de cada Estado miembro pueden ser decididos de acuerdo con las normas

5. Comisión Jurídica del Parlamento Europeo, Informe relativo a la primacía del Derecho Comunitario sobre el derecho de los Estados Miembros. Traducción y publicación del Instituto Interamericano, Relaciones entre el derecho comuntario y el derecho nacional, pág. 69. 
procesales establecidas en los actos comunitarios y particularmente, en el artículo 177 del Tratado de la CEE, que dispone:

"La Corte de Justicia es competente para estatuir a título prejudicial - a) sobre la interpretación del presente Tratado, -- b) sobre la validez y la interpretación de los actos tomados por las instituciones de la Comunidad, - c) sobre la interpretación de los estatutos de los organismos creados por un acto del Consejo, cúando los estatutos lo prevean."

La crítica más prudente de esta teoría ha sido formulada por IPSEN ${ }^{6}$, quien se expresa así:

"La solución precesal no puede en consecuencia resolver nuestro problema fundamental. Más todavia, ello ha sido reconocido por Jaenicke en su último estudio sobre esta cuestión: a la Corte no se le debe preguntar sobre si el derecho comunitario debe primar sobre el derecho nacional de acuerdo a la posición legal o constitucional interna. La pregunta que debe hacerse a la Corte, continúa Jaenicke, y sobre la cual debe dictar una decisión obligatoria, es en que medida el Tratado, correctamente interpretado, obliga al Estado a aceptar la primacía del derecho comunitario sobre el derecho nacional en caso de conflicto."

Y más adelante agrega:

"Estoy conciente de que Wohlfarth está en desacuerdo pues, en el caso del conflicto entre el derecho comunitario y el derecho nacional, incluye

6. IPSEN, H. P., The Relationship between the Law of European Communities and National Law, Common Market Law Review, March, 1965, pág. 381 y sig. 
entre los efectos de la declaración de la Corte de Justicia que pronuncia la nulidad del derecho nacional el de la obligatoriedad de esta declaración para los tribunales nacionales."

\section{C) Teoría pragmática.}

La aplicación de los principios tradicionales con todos sus efectos prácticos es lo que caracteriza la actitud de esta teoría, como solución para los conflictos de derechos. Y a esto se debe agregar que el sistema del pragmatismo sostiene el principio de la prevalencia de las reglas jurídicas nacionales sobre el derecho comunitario, o sea, in dubio pro comunitate.

Pero la teoría pragmática ha sido asimismo criticada por IPSEN. De hecho, en su opinión los límites de la cuestión de la preeminencia de un ordenamiento u otro del derecho "no satisfará a quienes consideran el problema de la primacía como una espécie de profesión de fé en la integración y una prueba de la estructura y naturaleza jurídica de las Comunidades, que la habilita a decidir si acaso la integración económica puede ser un paso preliminar hacia una integración de mayor escala y se acaso las constituciones de los Estados miembros están adaptadas, no solo para asegurar el respecto de los Tratados sino también para proveerles con las 'armas' internas apropiadas para la integración."

\section{D) Teoría del efecto útil.}

Se trata de una corriente doctrinaria propuesta por IPSEN y se basa en la "necesidad de segurar una capacidad de funcionamiento a las Comunidades a través del principio de la efectividad; no se toman en consideración abstracciones como la naturaleza jurídica de las Comuni-

7. IPSEN, H. P., op. cit., The Relationship..., pág. 387. 
dades, sino el rol de las normas jurídicas para la Comunidad. Interpretando la definición de Reglamento que contiene el artículo 189 del Tratado de la CEE de acuerdo al principio de la efectividad, no se considera que sus efectos no son solo el conferir el carácter de 'self-executing' a las regulaciones; valor y calidad que consistirían, simplemente, en su carácter comunitario, de naturaleza inviolable y que lo hace aplicable uniformemente a través de la Comunidad y, por lo tanto, no puede ser modificado por uno o varios Estados miembros."8

E) Teoría internacionalista.

De acuerdo a las concepciones de esta teoría planteada por Paul de Visscher y Scheuner9, las relaciones entre el Derecho Comunitario y el Derecho Nacional presenta los siguientes fundamentos:

a) La naturaleza del acto constitutivo de las Comunidades es la de un Tratado internacional;

b) Todos los elementos dinámicos de las Comunidades Europeas estarían subordinadas a este carácter 'INTERNACiONAL' $\mathrm{y}$, además se destaca que diversas organizaciones internacionales han gozado de similares facultades y características;

c) Los Tratados de las tres Comunidades Europeas obligan a los Estados miembros a ejecutarlos y a abstenerse de medidas que puedan resultar incompatibles, e incluso reconociendo que las Comunidades tienen un campo de

8. IPSEN, H. P., op. cit., págs. 393 a 402.

9. De Visscher, P., La CECA et Les Etats membres, Rapport au Congrès de Stresa, citado por Catalano, in Manual del Derecho de las Comunidades, Buenos Aires, 1966, pág. 716 - SchEUnER, citado por IPSEN, op. cit., pág. 381 . 
jurisdicción propio que les permite dictar normas, aplicar sanciones y recurrir a la Corte de Justicia.

Sin embargo, Hallstein critica esta teoría, y nosotros acompañamos esta tésis, señalando que "los alcances o poderes del derecho internacional público tradicional contradicen la voluntad de los Estados signatarios, manifestada en el Tratado, de fundar una Comunidad indisoluble en la cual se fundirán de manera irrevocable las economías nacionales... A este fin los Estados han transferido definitivamente algunos de sus derechos a la entidad Comunitaria que han creado. Ellos no pueden anular dicha transferencia por medidas ulteriores, unilaterales e incompatibles con el espiritu de la Comunidad... En segundo lugar, esta tésis no tiene en cuenta el principio del Tratado según el cual ningún Estado miembro puede cambiar la naturaleza específica del Derecho Comunitario, que ha de aplicarse uniforme $y$ totalmente en el conjunto de la Comunidad." 10

No obstante, la importancia que podemos atribuir a las teorias planteadas, creemos que ellas deben ser rechazadas, porque sus autores han hecho extensiva la expresión 'Comunidades Internacionales' a conceptos prácticos o institucionales que no merecen tal clasificación y no han elucidado completamente sus funamentos.

F) Teoría del federalismo.

La opinión 'Federalista' mucho más satisfactoria que las precedentes, refleja atualmente dominante en la Literatura Jurídica Internacional.

10. Walter Hallstein, La Comunidad Europea. Nuevo Order Jurídico. Conferencia pronunciada en la Facultad de Drecho y Ciencias Económicas de París, 1964, Publicación del Instituto Interamericano de Estudios Jurídicos Internacionales, págs. 20 y 21. 
En efecto, la tésis sobre el Federalismo demuestra perfectamente las dimensiones entre el Derecho Comunitário y el derecho nacional y revela la verdadera naturaleza jurídica de las Comunidades Europeas, cuyo sistema está basado en un equilibrio de competencias. Sostienen esta tésis Ophüls, Hallstenn, Catalano y Wohlfarth. A estos nombres debemos agregar lo de JEAN Victor Louis, quien, sin embargo, hace algunas reservas en lo que concierne a esta teoria.

Según los autores de la tésis denominada Federalista, los tratados de la Integración Europea tienen una estructura de tipo federal puesto que no se asemejan a las organizaciones internacionales tradicionales. Realmente, tales Tratados revelan la existencia de un contenido nuevo y diverso de los conocidos en el derecho internacional.

Otro argumento que sustenta la realidad de la tésis del Federalismo es lo que respecta a las transferencias de soberanía, por vía legislativa, realizadas en favor de las Comunidades, y cuya fuente está en el artículo 24 de la Constitución alemana. En efecto, dispone ese artículo: "La Federación podrá transferir por vía legislativa los derechos de soberania a instituciones internacionales."

A este respecto debemos señalar la opiniõn de HallSTEIN :

"Siendo el Derecho Comunitario un orden jurídico particular, es importante ver cual es su posición con relación al derecho nacional. En este sentido conviene no solamente tomar en consideración el derecho de los Estados miembros sino también hacer referencia a los posibles conflictos con los sistemas de terceros Estados. Con los progresos de la integración esos conflictos serán más y más frecuentes en los dominios del derecho administrativo, del derecho civil y en particular en el derecho de la competencia. La razón es el fuerte incremento de la economia del mundo occidental. 
Para poder reglar sus conflictos de leyes la Comunidad debe tener su propio derecho internacional privado y administrativo, sin que sea necesariamente un derecho escrito. En lo que concierne a la cuestión del lugar del derecho comunitario en relación con el derecho nacional de los Estados miembros, no se trata ya de saber si debemos remitirnos a un sistema jurídico o a otro, es decir, no se trata más de relaciones entre sistemas jurídicos cerrados colocados uno en frente de otro de una manera dualista. Por el contrario, el derecho comunitario y el derecho de los Estados miembros se complementan. Ellos se conectan el uno con el otro en muchos sentidos y se aplican en el mismo espacio jurídico de manera que los tribunales y los ciudadanos deben aplicar esos dos derechos concurrentemente." 11

De otra parte, es de Hallstern una de las mejores definiciones formuladas sobre la naturaleza jurídica del derecho comunitario, cuando expresa que "El orden jurídico de la Comunidad es un conjunto completo de principios jurídicos que han creado el Tratado de Roma y los actos de las Instituciones en aplicación del Tratado."

En lo que respecta el examen de los reglamentos de las Comunidades y la aplicación del Derecho Federal bajo los principios de la teoría federalista es de un gran interés doctrinario y práctico la tésis sostenida por el Professor JeAN Victor Louis quien subraya que:

"La conception dite 'fédéraliste' des rapports entre le droit communautaire et le droit national n'a pas rallié la doctrine et la jurisprudence pour

11. WAlter Hallstein, La Comunidad Europea, Nuevo Orden Jurídico. Conferencia pronunciada en la Facultad de Derecho y Ciencias Económicas de París, 1964, Publicación del Instituto Interamericano de Estudios Jurídicos Internacionales, pág. 19. 
ces raisons et pour des motifs d'ordre plus général. On ne peut nier qu'en droit fédéral, la primauté de ce dernier vienne de la nature même de la structure fédérale qui implique une répartition des compétences. Il n'est pas légitime de transposer, sans plus, pour le droit communautaire des règles conçues dans un cadre étatique, alors même que l'on peut douter de l'existence d'une telle répartition. La doctrine sous l'impulsion des institutions de la Communauté, et en premier lieu de la Comission et de la Cour a cherché, dès lors, une orientation nouvelle. Les analogies de celle-ci, avec la thèse dite 'fédéraliste' sont nombreuses. L'importance des tentatives nouvelles justifie cependant un examen séparé."12

Para terminar el examen de la materia sobre las relaciones Derecho Comunitario y derecho nacional, cabe citar la Resolución acerca de la primacía del Derecho Comunitario adoptada por el Parlamento Europeo, el 26 de abril de 1965, la cual establece que "EI Parlamento hace suyas las conclusiones del Informe de su Comisión Jurídica tendientes a afirmar el princípio de la supremacía del Derecho Comunitario sobre el Derecho Interno de cada uno de los Estados miembros."

Concluimos la exposición de esta materia, y así creemos justificar la primacía del Derecho Comunitario sobre el Derecho Nacional, sosteniendo la tésis denominada Federalista no obstante las Comunidades Europeas poseer una estructura sui generis. La naturaleza juridica de las Comunidades es pues, de tipo federal y su fundamento está en la transferencia de derechos de soberanía por vía legislativa.

12. JEAN Victor Louis, Les Pèglements de la Comunauté Economique Européenne, Institut d'Etudes Européennes Université Libre de Bruxelles, Thèses et Travaux Juridiques, 1969, pág. 398. 


\section{CAPÍTULO TERCERO}

Compettencia de la corte de justicia de las comunidades europeas.

En razón de su particular importancia, debe ser consagrado al examen de la Corte de Justicia de las Comunidades Europeas un desarrollo especial, es decir, el estudio de su estructura y de su competencia.

\section{a) Organización y Composición.}

La Corte de Justicia de las Comunidades Europeas es una Institución creada juntamente con el Tratado de Roma, de 25 de marzo de 1957, y como órgano soberano, tiene por finalidad el control jurisdiccional y de la legalidad de los actos de las Comunidades. Pero debemos señalar desde luego que se trata de un tribunal concerniente a las tres Comunidades Europeas, o sea, a la Ceca (incluso el Protocolo anexo), a la CEe y al Euratom (incluso los Protocolos anexos).

“La Corte è dunque l'istanza giurisdizionale propria dell'ordinamento comunitario: il che ha per conseguenza che essa interpreta, applica il diritto comunitario, dirime le controversie che sorgono rispetto al diritto comunitario".

\section{Afirma Riccardo Monaco ${ }^{13}$.}

De acuerdo con el artículo 165 de dicho Tratado de Koma, la Corte de Justicia se compone de siete jueces quienes son nombrados por los gobiernos miembros, entre personalidades que ofrezcan todas las garantías de independencia y que reúnan las condiciones de notoria competencia en materia de derecho.

13. RICARDo Honaco, Lezioni di Organizzazione Internazionale, Vol II, Torino, 1961, pág. 276. 
De otra parte, la Corte de Justicia es asistida por dos abogados generales quienes tienen el encargo de presentar públicamente las conclusiones orales sobre los asuntos sometidos a la Corte (art. 166), asimismo nombrados por los gohiernos miembros, con las mismas exigencias hechas a los jueces.

Los jueces y abogados generales son designados para un período de seis años, renovandose parcialmente cada tres años, podiesdo además ser reelegidos (art. 167).

Los Jueces y abogados generales de la Corte de Justicia de las Comunidades gozan de inmunidades y privilegios, pero no pueden desempeñar funciones políticas ni administrativas durante el ejercicio de sus funciones.

b) Funcionamiento.

En cuanto a su funcionamiento, la Corte de Justicia puede sesionar en pleno o en salas. En el plenario son discutidas: a) las cuestiones prejudiciales; b) problemas planteados por una institución o por un Estado miembro de las Comunidades. En las salas, que se componen de tres jueces y un abogado general, son juzgados los asuntos sometidos por el Presidente de la Corte.

Asimismo la Corte tiene la atribución de nombrar un Serretario por un periodo de seis años, y cuyas funciones principales son: a) asistir a las sesiones; b) levantar las actas; c) transmitir y conservar los documentos; d) efectuar las notificaciones; y e) ayudar a la Corte y a los jueces en los actos de su ministerio.

Los idiomas oficiales empleados en la Corte son el alemán, francés, holandés e italiano.

c) Competencia de la Corte de Justicia de las Comunidades Europeas.

De acuerdo con la normatividad establecida en los Tratados de las Comunidades Europeas, la Corte tiene 
competencia exclusiva para conocer de los problemas que puedan surgir entre los Estados miembros. Esta es también la posición de $\mathrm{A}$. DonneR ${ }^{14}$ cuando subraya que "Au début de leurs sections concernant le pouvoir judiciaire communautaire, tous les trois traités ont caractérisé l'essence de son rôle par une disposition quasi identique: "La Cour de Justice assure le respect du droit dans l'interprétation et l'application du traité" (art. 164 c.E.E., art. 136 C.E.E.A., art. 31 c.E.C.A. légèrement différent). C'est l'adage principal qui revient régulièrement dans l'élaboration de la compétence judiciaire. La Cour est garante que les traités et les règles communautaires sont des instruments de droit, interprétés et appliqués en tant que tels d'une part obligeant la Communauté à l'égard des Étatsmembres et leurs sujets, d'autre part obligeant les Etats membres entre eux, vis-à-vis de la Communauté même et envers leurs propres sujets."

Primeramente se incluyen en su competencia los recursos generales de nulidad concernientes a los actos emanados de la Alta Autoridad de la CeCa y de las Comisiones y Consejos de la Cee, y Euratom. Pero su función esencial consiste en garantir el respecto del Derecho de la interpretación y en la aplicación del tratado y de los reglamentos de ejecución.

La Corte debe juzgar la conformidad del comportamiento de los órganos de la Comunidad a las normas del Tratado y a las normas que le dán ejecución. Por lo tantose debe excluir la posibilidad que las partes interessadas puedan encontrar en otra esfera, por ejemplo en un juicio arbitral o junto a la Corte Internacional de Justicia la

14. A. DonNeR, Les Rapports entre la Compétence de la Cour de Justice des Communautés Européennes et les Tribunaux Internes, in Recueil de Cours de l'Académie de Droit International de la Haye, 1965, vol. II, tome 15, pág. 11. 
tutela jurisdiccional de los derechos y de los intereses conexos con el ordenamiento de la Comunidad. ${ }^{15}$

Estos recursos generales de nulidad pueden ejercerse por los Estados miembros en contra de los Consejos, Alta Autoridad y Comisiones; por los Consejos en contra de la Alta Autoridad y Comisiones; y por la Alta Autoridad o Comisiones contra los Consejos. En los Tratados de Roma también pueden ejercerlos las personas fisícas y morales, si se trata de un acto individual deberán ser su destinatario y si se trata de un acto general deberá afectarlo direta e individualmente. En el Tratado de la CECA pueden ejercerlo las empresas y asociaciones, salvo en contra del Consejo; si se trata de un acto individual debe afectar al particular y si se trata de un acto general debe estar viciado de desviación de poder respecto de ese particular.

En lo que respecta a los recursos especiales de nulidad, sus dispositivos se encuentran en los artículos 63 del Tratado de la CECA (sobre compradores que han infringido las normas sobre precios); art. 66 (sobre la concentración de empresas).

Por otra parte, el artículo 18 del Tratado del Euratom admite un recurso contra las decisiones del Comité de Arbitraje, previsto para el otorgamiento de licencias.

\section{Los recursos a tìtulo prejudicial}

Abordamos ahora una de las cuestiones más importantes contenidas en el Tratado de Roma, de 25 de marzo de 1957, sobre la competencia, es decir, la competencia a título prejudicial.

En efecto, dispone el artículo 177 del Tratado de Roma (CEE) que la Corte de Justicia es competente para estatuir a título prejudicial, sobre la interpretación del Tratado respectivo.

15. Riccardo Monaco, op. cit., pág. 283. 
Se trata pues de uno de los aspectos más delicados de la posible concurrencia de jurisdicción entre los Tribunales de los Estados miembros y la Corte.

Es el artículo 177 por lo tanto, que fija la regla de la prejudicialidad siempre que sea necesaria la interpretación del Tratado, de la validez y de la interpretación de los actos ejecutados por los órganos comunitarios, y también por la interpretación de los Estatutos de los organismos creados con actos del Consejo.

Y sobre la prejudicialidad así se manifiesta DONNER:16

"Une seule maxime semble dominer l'attitude de la Cour en matière préjudicielle: exerecer sa tâche coordinatrice dans le respect des compétences et de la liberté que l'article n. 177 làisse aux juridictions nationales. 'L'objet de l'article est suffisamment inusité et innovateur pour ne pas compliquer sa réalisation par l'introduction d'objetifs de nature secondaire. La vocation d'assurer l'application uniforme du droit communautaire demande de la part des pouvoirs judiciaires nationaux une grande abnégation et l'abandon de beaucoup de convictions enracinées et d'habitudes chères et fortes."

Podemos concluir por lo tanto, a la luz de las reglas jurídicas contenidas en los Tratados de la CECA (art. 41), del Euratom (art. 18) y muy particularmente del Tratado de la CEE (art. 177), en lo que respecta a los recursos prejudiciales, que el objetivo de la Corte de Justicia de las Comunidades Europeas es asegurar la unidad del derecho comunitario. Y realmente, esta es la solución desde que un problema sea planteado ante una jurisdicción nacional, pero por sus características, necesite del pronunciamiento de la Corte.

16. A. DONNER, op. cit., pág. 25. 


\section{Competencia consultiva}

En lo que respecta a la Competencia Consultiva de la Corte de Justicia, esta se verifica cuando los Tratados de las Comunidades y losacuerdos internacionales necesiten el pronunciamiento acerca de su compatibilidad.

\section{El procedimiento}

Desde el punto de vista del procedimiento lo que se observa es que sigue las mismas características verificadas en los tribunales nacionales. El procedimiento por lo tanto, puede ser ordinario o especial con las fases escritas y orales. Tras las conclusiones del abogado general es dictado el fallo.

\section{CAPÍtulo CUARTo}

El derecho comunitario y la jurisprudencia de la corte de justicia de las comunidades

El problema de la primacia del Derecho Comunitario sobre las normas juridicas de derecho nacional ha sido planteado principalmente y con toda amplitud ante la Corte de Justicia de las Comunidades Europeas en el Asunto Flaminio Costa contra el E.N.E.L. (Ente Nazionale Energia Elettrica) ${ }^{17}$

El Abogado de Milán, Sr. Fiaminio Costa, pretende no deber una factura de valor 1.925,00 Liras Italianas (cerca

17. Cour de Justice des Communautés Européennes - Recueil de la Jurisprudence de la Cour, Fascicule n. 5, vol. X, 1964, Luxembourg. 
de tres dollares norte americanos), que por suministro de electricidad le reclama el E.N.E.L. (Ente Nazionale per l'Energia Elettrica). Dicho Abogado presentò su caso ante el juez conciliador (Giudice Conciliatore) de Milán, competente en primera y última instancia, por razón del monto de la solicitud, aduciendo que la ley 1643, de 6 de diciembre de 1962, que nacionalizó la industria electrica en Italia, era contraria a algunas de las disposiciones del Tratado de Roma e inconstitucional.

El 20 de febrero de 1964, el juez conciliador (Giudice Conciliatore) de Milán, por su turno, presentó a la Corte de Justicia de las Comunidades Europeas una solicitud de decisión prejudicial sobre el alcance del artículo $177 \mathrm{del}$ Tratado de la C.e.e. (Tratado de Roma, de 25 de marzo de 1957) en el dicho litigio.

La Corte tuvo de examinar las siguientes cuestiones antes de fallar:

I) Cuanto a los Fundamentos de Hecho y de Derecho:

a) Las disposiciones de la Ley 1643 , de 6 de diciembre de 1962 de la Republica Italiana sobre la nacionalización de la producción de la energía eléctrica;

b) El juez conciliador de Milán ha acogido la solicitud del Sr. Costa afirmando haber existido violación de los artículos 102, 93, 53 y 37 del Tratado.

II) En lo que respecta a las observaciones presentadas de conformidad con el artículo $20 \mathrm{del}$ Estatuto de la Corte:

a) La procedencia de la cuestión prejudicial (el Gobierno Italiano formuló agravios ante el juez conciliador; 
b) El artículo 177, que no puede ser utilizado para permitir que una autoridad nacional por iniciativa de un nacional de un Estado miembro subordine la aplicación de una Ley del Estado a la procedencia de la cuestión prejudicial por violación de las obligaciones del Tratado;

c) La interpretación de los artículos 102, 93, 53, 37 y 177.

Considerando pues, las observaciones formuladas por la Comisión de la Comunidad Económica Europea, el Grobierno Italiano y las Partes. Considerando además, las conclusiones del Abogado General; el Protocolo sobre el Estatuto de la Corte de Justicia de la Comunidad Económica Europea; las reglas de procedimiento de la Corte de Justicia de las Comunidades Europeas, la Corte dictaminando sobre la excepción de la inadmisibilidad basada en el artículo 177, falló sosteniendo la siguiente tésis:

"Las cuestiones planteadas por el Juez Conciliador (Giudice Conciliatore) de Milán, en virtud de lo dispuesto por el artículo 177 son admisibles en cuanto se refieren, en este caso a la interpretación de las disposiciones del Tratado de la CEe, y ningún acto unilateral posterior puede oponerse a las reglas de la Comunidad. Así juzgado en Luxemburgo el 15 de julio de 1964."

Lo que se observa pues, es que está implicita la tésis de la primacía de las normas comunitarias y existe la limitación de los derechos soberanos de los Estados miembros. Dentro del marco del procedimiento prejudicial, la Corte no puede, ni aplicar el Tratado al caso concreto ni dictaminar sobre la validez de las medidas del derecho 
interno respecto a éste, como le sería posible hacerlo dentro del marco del artículo 169 . La Corte puede, no obstante, extraer de las disposiciones incorrectamente formuladas por la jurisdicción nacional, aquellas cuestiones que solamente se refieren a la interpretación del Tratado.

De acuerdo con los estudios que hemos hecho sobre la naturaleza jurídica de las Comunidades Europeas, el examen del asunto Costa - E.N.E.L. nos autoriza expresar las seguientes conclusiones:

a) Las Comunidades Europeas constituyen una entidad de tipo federal autónoma en cuanto a sus decisiones, teniendo en cuenta los derechos de soberania que los Estados miembros les han otorgado, para la persecución de sus fines;

b) Según los textos de los Tratados de las Comunidades Europeas no solo los Estados miembros sino tambien los nacionales de estos quedan subordinados a la jurisdicción de la Corte de las Comunidades;

c) La Corte de Justicia de las Comunidades Europeas, al dictaminar el fallo en la litis consabida ha sostenido la primacía de su competencia, basada en el artículo 177 del Tratado de la Comunidad Económica Europea, y por consiguiente, reafirmó la regla según la cual la naturaleza de las Comunidades se caracteriza como un orden jurídico propio, integrado en los sistemas jurídicos de los Estados miembros a partir de la entrada en vigor del Tratado.

\section{Bibliografia}

Anziloti, E., Il Trattato del Mercato Comune, introduzione al vol. "Comunità económica europa ed Euratom", a cura della Società Italiana per l'Organizzazione Internazionale", Padova, 1957.

Cansacchi, Giorgio, Les éléments fédéraux de la Communauté Économique Européenne. "Mélanges en l'honneur de Gilbert Gidel", Paris, Sirey, 1961, págs. 91-104. 
Catalano, Nicola, 1) Aspectos Ideológicos, Económicos, Políticos y Jurídicos de la Integración Económica Europea, in Anuario Uruguayo de Derecho Internacional, IV, 1965, pág. 40.

2) Manual de Derecho de las Comunidades Europeas INTAL, Buenos Aires, 1966.

3) Les Sources du droit des Communautés Européennes, Centre Français de droit comparé, Paris, 1961.

Colliard, Claude Albert, Une vue d'emsemble sur l'application de l'article 177 du Traité de Rome. D. 1964 - Cronique, pág. 9.

CONSTANTINIDÈs-MÉGRET, Collette, Le Droit de la Communauté Économique Européenne et l'Ordre Juridique des États membres, Paris, 1967 (Bibliothèque de Droit Internacional).

Donner, A., Les Rapports entre la compétence de la Cour de Justice des Communautés Européennes et les Tribunaux Internes, in Recueil de Cours de L'Académie de Droit International de la Haye, 1965, vol. II, tome 115.

GaNshoF VAN DER MEERSCH, W. J., Organisations Européennes, Les Institutions, vol. I-II - Université Libre de Bruxelles, Presses Universitaires de Bruxelles, 1963.

GAUDET, Michel, Información Sumaria sobre la cuestión Constitucional, en los seis Estados miembros de las Comunidades Europeas, in La Integración Económica de América Latina y la cuestión Constitucional — Washington, 1967, pág. 75.

HaLlstein, Walter, La Comunidad Europea. Nuevo Orden Juridico, Conferencia pronunciada en la Facultad de Derecho y Ciencias Economicas de la Universidad de Paris, 1964 - Publicaciōn del Instituto Interamericano de Estudios Jurídicos Internacionales -

IPSEN, Hans Peter, Rapport du droit des Communautés Européennes Washington, 1967, avec le droit national, "Le Droit et les Affraires", 1964, n. 47.

LAGRANGE, Maurice de, La Cour de Justice des Communautés Européennes, "Etudes et Documents du Conseil d'Etat", Paris, fasc. 17, 1964, pp. 55-79.

LouIs, Jean-Victor, Les Règlements de la Communauté Économique Européenne (Institut d'Etudes Européennes, Université Libre de Bruxelles, 1969).

Megret, Jacques, La Communauté Economique Européenne (Jurisclasseur de Droit International), 1959, 163-164 A, $164 \mathrm{~B}, 164 \mathrm{C}$.

Monaco, Riccardo, Lezioni di Organizzazione Internazionale - Il Diritto Degli Enti Economici Internazionali, Torino, 1961 (E. Giappichelli). 
Ophuls, C. F., Les Problèmes des Dispositions directement applicables (self-executing) des Traités Internationaux et son application aux Traités instituant les Communautés. Rapport national allemand au 2e. Colloque International de Droit Européen, La Haye, 1963.

VIsscher, Paul de, Les tendences internationales des Constitutions modernes "Recueil de Cours de l'Académie de Droit International de la Haye", tome 80, 1952, pp. 511-578.

Zannini, W., La Giurisdizione della Corte di Giustizia delle Comunita Europee in rapporto agli ordinamenti degli Stati Membri. Diritto Internazionale, 1962, I, p. 242. 